\title{
PENGARUH KUALITAS PELAYANAN RECEPTIONIST TERHADAP KEPUASAN TAMU DI HOTEL PUSAKO BUKITTINGGI
}

\author{
Yandri Andika Rahmat.M ${ }^{1}$, Waryono² Pasaribu $^{2}$ \\ Program Studi D4 ManajemenPerhotelan \\ Jurusan Pariwisata \\ FPP Universitas Pariwisata \\ Email: yandika17@gmail.com
}

\begin{abstract}
This study aims to determine the effect of the quality of receptionist services on guest satisfaction at the Pusako Hotel Bukittinggi. This type of research is quantitative descriptive with associative causal methods. The purposive sampling used as many as 93 guests who had or were staying at Pusako Bukittinggi Hotel In the period of January-June 2017, data was collected through questionnaires with a Likert scale that had been tested for validity and reliability. The results obtained from this study are as follows: 1) Service Quality of Hotel Employees is in the poor category with a percentage value (58\%), 2) Guest Satisfaction is in a less satisfied Category at Pusako Bukittinggi Hotel with a percentage value (53\%). 3) The results of a simple linear regression test obtained a value of Fcount 29,667 with sig. 0,000<0,05 which means that variable $X$ can explain $Y$ variable significantly. Furthermore, the regression coefficient is 0.383 at a significant level of $0.000<0.05$. This means that each increase of 1 unit of service quality will increase 0.383 guest satisfaction units, and the $R$ square value of 0.246 means that the effect of variable $X$ on $Y$ variable is 0.246 (24.6\%) while the remaining $75.4 \%$ is influenced by other factors. So the service quality variable affects the guest satisfaction variable, so Ha is accepted.
\end{abstract}

Keywords: Service Quality, Guest Satisfaction

\section{A. Pendahuluan}

Salah satu bisnis yang berkembang pesat yaitu bisnis perhotelan. Perkembangan bisnis hotel tidak hanya berada pada kota besar, namun kota kecil pun tak kalah saing dalam menjalankan bisnis perhotelan tersebut. Hotel merupakan salah satu industri modern yang dapat membangun pariwisata sebuah negara. Tidak hanya itu, bisnis perhotelan dapat memberikan prospek yang menjanjikan ke depannya jika dikelola dengan baik. Maka dari itu, banyak pengusaha yang tertarik untuk mengembangkan bisnis perhotelan tersebut. Hotel Pusako merupakan salah satu hotel berbintang $4 \quad(* * * *)$ di kota Bukittinggi, yang terletak di Jln. Soekarno Hatta no. 7, Manggis Ganting, Mandiangin Koto Selayan, Kota Bukittinggi Sumatera Barat. 
Banyaknya perusahaan jasa perhotelan yang bermunculan menyebabkan persaingan antar hotel untuk menarik tamu. Keadaan ini merupakan suatu tantangan yang harus dihadapi pengusaha perhotelan untuk memenangkan persaingan. Dalam menghadapi persaingan tersebut, setiap hotel harus memiliki keunggulan bersaing dalam memberikan fasilitas dan pelayanan jasa perhotelan untuk dapat terus bertahan pada produk dan jasa yang ditawarkan kepada tamu hotel. Hal utama yang harus dilakukan untuk meraih keunggulan bersaing tersebut adalah dengan fokus kepada tamu hotel, salah satunya yaitu dalam menciptakan kepuasan tamu.

Kepuasan tamu menurut Setiawati (2009: 12) "Suatu tingkatan dimana kebutuhan, keinginan dan harapan dari tamu dapat terpenuhi yang akan mengakibatkan terjadinya pembelian ulang atau kesetiaan yang berlanjut". Hal yang jadi penentu kepuasan tamu terlihat dari lima indikator kepuasan tamu dimana, menurut Permana (2013: 24) yaitu "Tercapainya harapan atau tujuan tamu, terpenuhinya kebutuhan tamu, tercapainya keinginan tamu, adanya keinginan untuk memakai jasa atau produk itu kembali, adanya keinginan untuk merekomendasikan barang atau jasa kepada orang lain". Banyak perusahan di Sumatera Barat tepatnya Bukittinggi yang bergerak dibidang jasa sangat memperhatikan kepuasan.

Ada beberapa upaya dalam menciptakan kepuasan tamu dengan melihat dari beberapa faktor yang mempengaruhinya. Salah satu faktor tersebut yaitu kualitas pelayanan, hal ini sejalan dengan pendapat Parasuramandalam Hardiyansyah (2011: 92), mendefinisikan sebagai berikut:

"Penilaian kualitas pelayanan sebagai suatu pertimbangan global atau sikap yang berhubungan dengan keunggulan (superiorty) dari suatu pelayanan. Penilaian kualitas pelayanan sama dengan sikap individu secara umum terhadap kinerja perusahaan. Selanjutnya, ditambahkan bahwa penilaian kualiatas pelayanan adalah tingkat dan arah perbedaan antara harapan dan persepsi pelanggan."

$\begin{array}{clr}\text { Kualitas } & \text { pelayanan dapat } \\ \text { diketahui } & \text { dengan } & \text { cara }\end{array}$
membandingkan persepsi para tamu atas layanan dengan layanan yang benar-benar mereka menciptakan kepuasan bagi tamunya. Setelah tamu merasa puas dengan produk dan jasa yang diterimanya tamu akan membandingkan pelayanan yang diberikan. Apabila tamu benar-benar puas, mereka akan membeli ulang serta merekomendasikan kepada orang lain untuk membeli ditempat yang sama. 
Seorang receptionist haruslah melakukan kinerja yang baik, agar tamu merasa puas selama menginap di hotel. Salah satunya adalah dengan pelayanan prima. Kualitas pelayanan merupakan suatu bentuk penilaian konsumen terhadap tingkat pelayanan yang diterima (perceived services) dengan tingkat pelayanan yang diharapkan (expected services)Safitri (2016).

Berdasarkan observasi awal yang dilakukan peneliti pada 25 September 2017 dengan metode wawancara kepada 10 orang tamu yang berkunjung di Hotel Pusako Bukittinggi, ada beberapa permasalahan yang penulis rangkum mengenai kualitas pelayanan receptionist, seperti: 1) Karyawan receptionist di Hotel Pusako Bukittinggi tidak menggunakan uniform yang sama 2) Keinginan tamu untuk meminta kamar sesuai keinginan tidak terpenuhi 3) Pada saat tamu check in melalui travel agent seharusnya receptionist memberikan informasi kepada tamu bahwa kamar siap digunakan4) Barang tamu sering tertukar padasaat tamu menitip barang di receptionist 5) Sikap receptionist yang kurang ramah pada saat melayani tamu dan Kemampuan komunikasi receptionist kurang memuaskan terutama pada saat melayani tamu luar negeri.

Tujuan penelitian ini adalah untuk mengetahui kualitas pelayanan receptionist di Hotel Pusako
Bukittinggi, mengetahui kepuasan tamu di Hotel Pusako Bukittingi, menganalisis Pengaruh Kualitas Pelayanan receptionis tterhadap kepuasan tamu di Hotel PusakoBukittingi.

\section{B. Metode Penelitian}

Jenis penelitian ini adalahdeskriptif kuantitatif dengan metode assosiatif kausal. Sampel yang digunakan sampling purposive yaitu sebanyak 93 tamu yang pernah atau sedang menginap di Hotel Pusako Bukittinggi pada periode bulan Januari-Juni 2017. Data dikumpulkan melalui penyebaran kuesioner dengan skala likert yang telah teruji validitas dan reliabilitasnya.

Teknik pengumpulan data menggunakan kuesioner yaitu dengan cara memberikan atau menyebarkan daftar peryataan kepada responden sehingga mendapatkan jawaban, tanggapan, dan informasi yang diperlukan oleh peneliti. Teknik analisis data memakai uji regresi linear sederhana yang bertujuan untuk menentukan pengaruh variabel $\mathrm{X}$ terhadap variabel Y. Kriteria pengambilan keputusan adalah :

1. Jika nilai signifikan $<0,05$, maka Ha diterima dan Ho ditolak

2. Jika nilai signifikan $>0,05$, maka Ho diterima dan $\mathrm{Ha}$ ditolak. 
Sedangkan untuk menentukan besar kecilnya pengaruh variabel $\mathrm{X}$ dan $\mathrm{Y}$ dapat ditentukan dengan rumus koefisien determinasi sebagai berikut :

\section{Hasil Penelitian dan}

\section{Pembahasan}

1.Hasil Penelitian

a. Kualiatas Pelayanan

Receptionist
Data kualitas pelayanan receptionist dikumpulkan memlalui pernyataan yangterdiri dari 25 butir pernyataan. Selanjutnya, angket disebarkan kepada 93 responden untuk dijawab. Untuk distribusi frekuensi kualitas pelayanan receptionist dapat dilihat pada tabel 1 dibawah ini:

Tabel 1.Distribusi Frekuensi Variabel Kualitas Pelayanan Receptionist di Hotel Pusako Bukittinggi

\begin{tabular}{|c|c|c|c|}
\hline Kategori & Skor & Frekuensi & Persentase \\
\hline Sangat baik & $\geq 100$ & 0 & $0 \%$ \\
\hline Baik & $83-<100$ & 39 & $42 \%$ \\
\hline Kurang baik & $\mathbf{6 6}-<\mathbf{8 3}$ & $\mathbf{5 4}$ & $\mathbf{5 8 \%}$ \\
\hline Tidak baik & $49-<66$ & 0 & $0 \%$ \\
\hline Sangat tidak baik & $<49$ & 0 & $0 \%$ \\
\hline \multicolumn{2}{|c|}{ Total } & 93 & $100 \%$ \\
\hline
\end{tabular}

Sumber: Hasil Olahan Data Primer (2018)

Berdasarkan tabel di atas, dapat dijelaskan bahwa dari 93 respondenmenyatakan kualitas pelayanan pada kategori kurang baik (58\%). Kualitas pelayanan dengan indikator tangible responden menyatakan kurang baik (40\%) dan indikator lainnya reliability, responsiveness, assurance, dan emphaty responden menyatakan baik, secara berurutan masing-masing sebesar (56\%), (44\%), (46\%), (39\%).

\section{b. Kepuasan Tamu}

Data kepuasan tamu dikumpulkan melalui pernyataan yangterdiri dari 14 butir pernyataan. Selanjutnya, angket disebarkan kepada 93 responden untuk dijawab. Untuk distribusi frekuensi kepuasan tamudapat dilihat pada tabel 2 dibawah ini: 
Tabel 2. Distribusi Frekuensi Data Variabel KepuasanTamu di Hotel PusakoBukittinggi

\begin{tabular}{|c|c|c|c|}
\hline Kategori & Skor & Frekuensi & Persentase \\
\hline Sangat baik & $\geq 55,99$ & 5 & $5 \%$ \\
\hline Baik & $46,66-<55,99$ & 39 & $42 \%$ \\
\hline Kurang baik & $\mathbf{3 7 , 3 4 - < 4 6 , 6 6}$ & $\mathbf{4 9}$ & $\mathbf{5 3 \%}$ \\
\hline Tidak baik & $28,01-<37,34$ & 0 & $0 \%$ \\
\hline Sangat tidak baik & $<28,01$ & 0 & $0 \%$ \\
\hline \multicolumn{2}{|r|}{ Total } & 92 & $100 \%$ \\
\hline
\end{tabular}

Sumber: Hasil Olahan Data Primer (2018)

Berdasarkan tabel di atas, dapat dijelaskan bahwa dari 93 orang menyatakan kepuasan tamupada kategori kurang puas (53\%). Kepuasan tamu dengan indikator terpenuhinya kebutuhan tamu, tercapainya keinginan tamu dan keinginan untuk memakai jasa atau produk kembali responden menyatakan kurang puas, secara berurutan masing-masing sebesar (49\%), (31\%), (52\%). Dua indikator lainya yaitu tercapainya harapan tamu responden menyatakan sangat puas $(60 \%)$ dan keinginan untuk merekomendasikan jasa atau produk ke orang lain responden menyatakan puas $(40 \%)$.

\section{c. Uji Persyaratan Analisis}

Berdasarkan uji persyaratan analisis terdapat hasil uji normalitas, uji homogenitas dan uji linearitas. nilai signifikan kualitas pelayanan dan kepuasan tamu adalah variabel kualitas pelayanan 0.525 dan untuk kepuasan 0.326 dengan nilai > dari 0.05, maka dapat dikatakan bahwa kedua data terdistribusi normal, hasil uji homogenitas nilai signifikan adalah 0.574 dengan taraf signifikan $>0.05$. Hal ini artinya nilai signifikan data lebih besar dari taraf signifikan. Sehingga dapat diambil kesimpulan bahwa data berasal dari populasi yang mempunyai varian yang sama atau data bersifat homogeny dan berdasarkan hasil linearitas nilai signifikan 0.737 lebih besar dari 0.05 yang artinya terdapat hubungan linear secara signifikan antara variabel kualitas pelayanan (X) dan kepuasan Tamu (Y). Nilai signifikan dalam uji $\mathrm{F}$ hitung sebesar 0.789 dan Ftabel sebesar 1.70 maka $0.789<$ 1.70 dapat disimpulkan bahwa terdapat hubungan linear antara variabel kualitas pelayanan (X) dengan kepuasan tamu (Y).

\section{d. Uji Hipotesis}

Pengujian hipotesis digunakan untuk mengetahui derajat hubungan (rxy) antarakualitas pelayanan dengan kepuasan tamu di Hotel Pusako Bukittinggi, Hipotesis dalam penelitian ini adalah: 
Ha: Terdapat pengaruh yang signifikan kualitas pelayanan receptionist terhadap kepuasan tamu di Hotel Pusako Bukittinggi
Ho: Tidak terdapat pengaruh yang signifikan kualitas pelayanan receptionist terhadap kepuasan tamu di Hotel Pusako Bukittinggi

Tabel 3. Koefisien Regresi Sederhana

Coefficients $^{\mathrm{a}}$

\begin{tabular}{||c|c|c|c|c|c|}
\hline \multirow{2}{*}{ Model } & \multicolumn{2}{|c|}{$\begin{array}{c}\text { Unstandardized } \\
\text { Coefficients }\end{array}$} & $\begin{array}{c}\text { Standardized } \\
\text { Coefficients }\end{array}$ & & \\
\cline { 2 - 4 } & $\mathrm{B}$ & Std. Error & Beta & \multirow{2}{*}{ T } & Sig. \\
\hline $\begin{array}{l}\text { (Constan } \\
\text { t) }\end{array}$ & 13.841 & 5.803 & & 2.385 & .019 \\
& & & & & \\
TOTAL & .383 & .070 & .496 & 5.447 & .000 \\
\hline
\end{tabular}

a. Dependent Variable: TOTALY

Sumber: Hasil Olahan Data Primer (2018)

Pada tabel di atas diketahui regresi linear sederhana sebagai berikut:

1) $\mathrm{a}=$ angka konstan dari Unstandardized Coefficients dalam kasus ini nilainya sebesar 13.841. Angka ini merupakan angka konstan yang mempunyai arti bahwa jika ada kualitas pelayanan (x) maka nilai konsisten kepuasantamu (y) adalah sebesar 13.841.

2) $b=$ angka koefisien regresi. Nilainya sebesar 0,383 , angka ini mengandung bahwa setiap penambahan satu satuan kualitas pelayanan (x) maka kepuasantamu (y) akan meningkat sebesar 0,383.

Karena nilai koefisensi regresi bernilai positif maka dikatakan bahwa kualitas pelayanan (x) berpengaruh positif terhadap kepuasantamu (y) sehingga persamaan regresinya adalah:

$$
\mathrm{Y}=13.841+0,383 \mathrm{X} .
$$

Tabel 4. Hasil Signifikasi ANOVA

ANOVA $^{b}$

\begin{tabular}{|l|c|c|c|c|c|}
\hline Model & $\begin{array}{c}\text { Sum of } \\
\text { Squares }\end{array}$ & Df & Mean Square & F & Sig. \\
\hline \begin{tabular}{l}
1 \\
\multicolumn{2}{|c|}{$\begin{array}{l}\text { Regressi } \\
\text { on }\end{array}$}
\end{tabular} & 536.781 & 1 & 536.781 & 29.667 & $.000^{\mathrm{a}}$ \\
\hline
\end{tabular}




\begin{tabular}{|l|l|l|l|l|}
\hline Residual & 1646.509 & 91 & 18.094 & \\
Total & 2183.290 & 92 & & \\
\hline
\end{tabular}

Sumber: Hasil Olahan Data Primer (2018)

Berdasarkan output di atas

variabel $\mathrm{Y}$ secara signifikan. Jadi

diketahui bahwa nilai $\mathrm{F}$ hitung

29,667 dengan tingkat signifikan variabel kualitas pelayanan sebesar $0,000<0,05$ yang artinya mempengaruhi variabel kepuasan variabel $\mathrm{X}$ dapat menjelaskan tamu, maka Ha diterima dan Ho ditolak.

Tabel 5.Hasil Koefisien Determinasi Variabel Kualitas Pelayanan dan Kepuasan Tamu Di Hotel Pusako Bukittinggi

Model Summary

\begin{tabular}{|l|r|r|r|r|}
\hline Model & \multicolumn{1}{|c|}{$\mathrm{R}$} & R Square & \multicolumn{1}{c|}{$\begin{array}{c}\text { Adjusted R } \\
\text { Square }\end{array}$} & $\begin{array}{c}\text { Std. Error of the } \\
\text { Estimate }\end{array}$ \\
\hline 1 & $.496^{\mathrm{a}}$ & .246 & .238 & 4.253 \\
\hline
\end{tabular}

a. Predictors: (Constant), TOTALX

Sumber: Hasil Olahan Data Primer (2018)

Output model summary, diketahui nilai koefisien determinasi ( $R$ Square) sebesar 0,246. Besarnya angka koefisien determinasi $(R$ Square) 0,246 sama dengan $24,6 \%$ dan sisanya $75,4 \%$.

\section{Pembahasan}

Berdasarkan hasil penelitian, maka dapat dibuat pembahasan tentang kualitas pelayanan dengan kepuasan tamuserta hubungan antara kedua variabel tersebut. Dari analisa dapat diketahui bahwa variabel independen (kualitas pelayanan) signifikan terhadap variabel dependen (kepuasan tamu). Penjelasan sebagai berikut:

\section{a. Kualitas Pelayanan}

Hasil deskripsi penelitian kualitas pelayanan di Hotel Pusako Bukittinggiditinjau dari indikator tangible, reliability,responsiveness, assurance dan emphaty. Hasil penelitian tentang kualitas pelayanan pada kategori kurang baik (58\%). Kualitas pelayanan dengan indikator tangible responden menyatakan kurang baik (40\%) dan indikator lainnya reliability, responsiveness, assurance, dan emphaty responden menyatakan baik, Secara berurutan masing-masing sebesar (56\%), (44\%), (46\%), (39\%).

Hasil analisis deskriptif kualitas pelayanan receptionist dikategorikan kurang baik. Hal ini menggambarkan bahwa Hotel 
Pusako Bukittinggi belum memberikan pelayanan yang baik kepada tamu. Hal ini sejalan dengan pendapat Tjiptono (2005: 121) "Apabila pelayanan yang diterima sesuai dengan yang diharapkan, maka kualitas pelayanan dipersepsikan baik dan memuaskan jika pelayanan yang diterimanya melampaui harapan pelanggan, maka kualitas pelayanan dipersepsikan ideal. Sebaliknya, jika pelayanan yang di terima rendah dari pada yang diharapkan maka kualitas pelayanan dianggap buruk".

\section{b. Kepuasan Tamu}

Hasil deskripsi penelitian kepuasan tamu di Hotel Pusako Bukittinggi ditinjau dari indikator tercapainya harapan tamu, terpenuhinya kebutuhan tamu, tercapainya keinginan tamu, keinginan untuk memakai produk/jasa itu kembali (loyal terhadap produk/jasa), keinginan untuk merekomendasikan barang dan jasa kepada orang lain. Hasil penelitian tentang kepuasan tamu pada kategori kurang puas (53\%). Kepuasan tamu dengan indikator terpenuhinya kebutuhan tamu, tercapainya keinginan tamu dan keinginan untuk memakai jasa atau produk kembali responden menyatakan kurang puas, secara berurutan masing-masing sebesar (49\%), (31\%), (52\%). Dua indikator lainya yaitu tercapainya harapan tamu responden menyatakan sangat puas (60\%), dan keinginan untuk merekomendasikan jasa atau produk ke orang lain responden menyatakan puas $(40 \%)$.

Berdasarkan penjelasan di atas, menunjukkan bahwa kepuasan tamu di Hotel Pusako Bukittinggi kurang puas, maka dari itu perlunya suatu usaha yang maksimal sehingga tercapainya harapan dan keinginan tamu sesuai dengan ekspetasi. Menurut Permana (2013: 23), "Kepuasan adalah perasaan senang atau kecewa seseorang yang timbul dari membandingkan presepsi tentang kinerja (hasil) dari suatu produk dengan harapan yang dimiliki. Jika kinerja gagal memenuhi harapan maka pelanggan akan kecewa. Jika kinerja menyamai harapan, pelanggan puas, jika kinerja melampaui harapan pelanggan amat puas dan terpukau".

\section{c. Pengaruh Kualitas Pelayanan Dengan Kepuasan Tamu di Hotel Pusako Bukittinggi}

Hasil uji regresi linier sederhana di peroleh nilai $F_{\text {hitung }}$ 29,667 dengan sig. $0,000<0,05$ yang artinya variabel $\mathrm{X}$ dapat menjelaskan variabel $\mathrm{Y}$ secara signifikan. Selanjutnya koefisien regresi sebesar 0,383 pada taraf signifikan $0.000<0.05$. Artinya setiap peningkatan sebesar 1 satuan kualitas pelayanan akan meningkatkan 0,383 satuan kepuasan tamu, dan nilai $\mathrm{R}$ square 0,246 artinya pengaruh variabel $\mathrm{X}$ terhadap variabel $\mathrm{Y}$ 
adalah sebesar $0,246 \quad(24,6 \%)$

sedangkan sisanya $75,4 \%$ di pengaruhi oleh faktor lain. Jadi variabel kualitas pelayanan mempengaruhi variabel kepuasan tamu, maka Ha di terima.

Kepuasan tamu sendiri dilihat dari berbagai aspek salah satu aspek tersebut adalah kualitas pelayanan. Kualitas pelayanan yang baik akan menimbulkan harapan dan keinginan yang baik, sehingga apabila pihak hotel tidak mampu memenuhi harapan tamu maka akan menimbulkan ketidakpuasan yang baik pula. Menurut Irawan (2003: 23), "Faktor-faktor yang mempengaruhi kepuasan pelanggan adalah mutu produk, mutu pelayanan, faktor emosional, harga, biaya dan kemudahan". Sedangkan menurut Buchari Alma (2009: 169), "Harga merupakan suatu atribut yang melekat pada suatu produk atau jasa dimana produk atau jasa tersebut dapat menjadi faktor yang mempengaruhi kebutuhan, keinginan dan kepuasan tamu yang dinyatakan dengan uang".

\section{Kesimpulan dan Saran}

\section{Kesimpulan}

a. Kualitas pelayanan receptionist di Hotel Pusako Bukittinggi dalam kategori kurang baik sebesar 58\%. Kualitas pelayanan indikator tangible respondenmenyatakan kurang baik $(40 \%)$ dan indikator lainnya reliability, responsiveness, assurance, dan emphaty
responden menyatakan baik,
secara berurut masing-masing
sebesar $(56 \%),(44 \%),(46 \%)$,
$(39 \%)$.

b. Kepuasan tamu di Hotel Pusako Bukittinggi dalam kategori kurang baik sebesar 53\%. Kepuasan tamu dengan indikator terpenuhinya kebutuhan tamu, tercapainya keinginan tamu, dan keinginan untuk memakai jasa atau produk kembali responden menyatakan kurang puas, secara berurutan masing-masing sebesar (49\%), (31\%), (52\%). Dua indikator lainya yaitu tercapainya harapan tamu responden menyatakan sangat puas $(60 \%)$, dan keinginan untuk merekomendasikan jasa atau produk ke orang lain responden menyatakan puas (40\%).

c. Hasil uji regresi linier sederhana di peroleh nilai $F_{\text {hitung }}$ 29,667 dengan sig. $0,000<0,05$ yang artinya variabel $\mathrm{X}$ dapat menjelaskan variabel $Y$ secara signifikan. Selanjutnya koefisien regresi sebesar 0,383 pada taraf signifikan $0.000<0.05$. Artinya setiap peningkatan sebesar 1 satuan kualitas pelayanan akan meningkatkan 0,383 satuan kepuasan tamu, dan nilai $\mathrm{R}$ square 0,246 artinya pengaruh variabel $\mathrm{X}$ terhadap variabel $\mathrm{Y}$ adalah sebesar $0,246 \quad(24,6 \%)$ sedangkan sisanya $75,4 \%$ di pengaruhi oleh faktor lain. Jadi 
variabel kualitas pelayanan mempengaruhi variabel kepuasan tamu, maka Ha di terima.

\section{Saran}

Manajemen diharapkan memperhatikan dan menumbuhkan kualitas pelayanan karyawan receptionist yang lebih baik lagi agar tamu merasa lebih puas dan nyaman. Hal ini bisa dilakukan oleh pihak manajemen dengan cara memberikan contoh grooming yang baik, dan memperbaharui peralatan kerja yang digunakan. Sehingga karyawan dapat menjalankan tugas dengan optimal dengan tujuan memenuhi semua harapan dari kepuasan tamu. Diharapkan para karyawan receptionist agar mematuhi segala peraturan hotel dan menjalankan job description dengan benar agar meningkatnya kualitas kerja, sehingga bisa terpenuhinya kepuasan tamu dan meningkatkan pendapatan hotel. Kepadapeneliti selanjutnya lebih mendalami aspek lain, seperti: aspek kepemimpinan, lingkungan kerja, kinerja dan kepuasan kerja serta faktor-faktor yang mempengaruhi kepuasan tamu seperti: kualitas produk, harga, emosional faktor dan biaya.

Catatan: Artikel ini disusun berdasarkan skripsi penulis dengan Pembimbing 1 Waryono, S.Pd, MM, Par danPembimbing II Pasaribu. SST, Par, M. Si Par.

\section{DAFTAR PUSTAKA}

Alma, Buchari. (2009). Manajemen Pemasaran dan Pemasaran Jasa. Cetakan Kedelapan. Bandung: Alfabeta.

Hardiyansyah, (2011). Kualitas Pelayanan Publik. Yogyakarta: Gava Media

Irawan, (2003). Manajemen Pemasaran Modern. Yogyakarta: Liberty Yogyakarta

Permana, (2013). Manajemen Marketing Perhotelan. Yogyakarta: CV. Andi Offset.

Setiawati, (2009). Study Kepuasan Pelanggan Untuk Mencapai Loyalitas Pelanggan. Semarang: Universitas Diponegoro.

Safitri, Erwina. (2016). Pengaruh Kualitas Pelayanan Dan Citra Perusahaan Terhadap Kepuasan Pelanggan dan Loyalitas Pelanggan Service Center Di Kota Malang. Malang: Universitas Brawijaya.

Tjipton, Fandy. (2005). Service, Quality \& Satisfaction. Yogyakarta: CV. Andi Offset. 